Child maltreatment

Review article

Paediatrics Today 2013;9(1):5-12

DOI $10.5457 / \mathrm{p} 2005-114.56$

\title{
SEXUAL ABUSE TODAY: PRESENT AND PERVASIVE
}

Lisa J. PFITZER

University of Louisville

Department of Pediatrics

Division of Pediatric Forensic

Medicine

Louisville, Kentucky, USA

Lisa J. Pfitzer

University of Louisville

Department of Pediatrics

Division of Pediatric Forensic

Medicine

210 East Gray Suite 702

Louisville, Kentucky, USA 40202

lisa.pfitzer@louisville.edu

Tel.: + 502-629-3099

Fax.: + 502-629-3096

Received: June 28, 2012

Accepted: January 10, 2013

Copyright (C) 2013 by

University Clinical Center Tuzla.

E-mail for permission to publish:

paediatricstoday@ukctuzla.ba
Sexual abuse continues to have a pervasive presence in our society, seriously affecting victims and their non-offending family members. Sexual abuse can be present in many different situations, whether within the family or the greater community, while the child is at school or participating in extracurricular activities, such as sports or arts. Furthermore, access to and exploitation of children seems to have endless potential in the relatively new world of electronics and the internet, as seen in the production of child pornography and child sex trafficking. Protecting children from these harmful scenarios remains at the heart of caring for the pediatric patient. Conclusion - Without doubt, sexual abuse persists, unthreatened and covert through traditional and now nontraditional venues. It is essential that health care providers are aware of the family, community and world conditions that so readily promote sexual abuse, and be ready to advocate and protect the most vulnerable members of our society.

Key words: Sexual abuse - Child pornography - Sex trafficking

\section{Introduction}

Sexual abuse continues to exist in today's society. It is said that reporting trends indicate an overall decline in sexual abuse events - for reasons unclear - yet daily reports of child sexual abuse are made to law enforcement and child protection agencies, health care clinicians continue to regularly evaluate these affected children, and news reports abound of child sexual abuse cases $(1,2)$. Perhaps more than ever before, unique opportunities to perpetuate child sexual abuse, such as child pornography production for the internet and the existence of human trafficking, offer 
readily available venues for perpetrators of sexual abuse. These more covert and global methods can be extremely challenging to defeat, simply due to the sheer number of people and geography involved.

This article will review the persistence of child sexual abuse situations in our everyday world and at every level in our society, including the family and local community, nationally and internationally. Health care providers should be aware that sexual abuse education and prevention remain an important priority when providing care to our children and teenagers.

\section{The medical evaluation of child sexual abuse}

Child sexual abuse has always been an enigma due to the intrinsic components of this unasked for sexual experience. The specific interaction between the child and the perpetrator creates complicated dynamics related to secrecy, fear, guilt, shame and loyalty, often hindering the child's capability for disclosure and the ability of non-offending adults to protect the child. The sexual abuse may go unreported, or the child may disclose, then retract the disclosure, with the realization that the family system is no longer intact (3). Medical research literature focusing on child sexual abuse examinations has evolved over the years, with increasingly rigorous studies yielding results with few definitive physical findings that could confirm the occurrence of sexual abuse. Berenson et al.'s (4) article about physical findings in pre-pubertal girls, who reported sexual abuse, as compared to a control group, who did not disclose sexual abuse, reported abnormal findings in less than five percent of the reported sexually abused females. These abnormal physical findings were identified as vaginal discharge, hymenal perforation, hymenal transection and a deep (hymenal) notch. An adolescent study of thirty-six pregnant teens, being evaluated for sexual abuse, revealed that four subjects had suggestive findings defined as deep notches and scars; and two females had definitive exams described as clefts in the lower half of the hymen that extended to the base of the hymen (5). It is now well established that the results of the physical examination are often normal (6). There is no one particular reason for this outcome but several possibilities include the usual delay in the child's disclosure of events, the ability of mucosal tissues to heal quickly and without scarring, sexual touching of a nature that is not physically injurious to the child, or similarly, sexual exposure that involved inappropriate activities, such as photos, but where no physical injuries would be expected. Further, sexually transmitted infections in this child population are not seen frequently $(7,8)$. It is generally believed that reports of sexual abuse during childhood is underestimated. However, some children actually disclose their abuse, whether accidental or purposeful. The developmentally able child can often use their words to describe what occurred to them, during the process of a recorded forensic interview. It is crucial to understand that child sexual abuse, unlike physical abuse, typically yields no "handprint" (bruising) pattern on the victim's skin for the clinician to measure and photodocument. The examiner must know that many times there will likely be nothing physically visual. Rather, the internal handprint of sexual exposure and sexual touching is in the heart and mind, otherwise unseen to those non-offending family and friends who would want nothing but love and safety for their child. Thus, the child's words are often the central focus of the investigation. The child can offer detail and a knowledge base that reflects their experiences. It is essential to believe the child's words (9). Children are not always believed however. Schaefer and colleagues (10) describe a unique study that was led by sexual abuse victims using an online sur- 
vey. Seventy percent of the participating male and female victims responded that they were not believed or the situation was not followed up, with many victims experiencing at least partial guilt about the situation (10). Finally, if the child later recants, the clinician must, in concert with investigators and advocate team members, be scrupulous in assessing the situation surrounding the retraction. The clinician should have high suspicion that an adult has instructed, perhaps even threatened, the child to change their story to protect the perpetrator and/or the advantages the perpetrator has provided to the family. The child's safety remains top priority.

\section{Child sexual abuse and the family}

Family dynamics can play a role in the development of child sexual abuse. A multitude of scenarios can create an environment that supports the initiation and maintenance of sexual abuse. Although girls are more likely victims of sexual abuse, boys can also be victims (11). It is generally believed that boys may not disclose sexual abuse as readily as girls, because victimization could indicate the child was unable to resist the perpetrator; the male child could be concerned about the appearance of homosexual behavior or not being as independent after the disclosure (12). The typical perpetrator is not a stranger; it is someone who is known to the child, often within the network of the family's relatives, friends or acquaintances. This person typically has ready access to the child, such as the mother's boyfriend, a sitter, an older (usually male) adolescent, a close family friend or neighbor, or someone found within the child's scope of activities - for example, a teacher, coach or minister. The parents may be very trusting of the perpetrator as a (long-time) family friend, or alternatively perhaps feel so overwhelmed with other responsibilities that they are grateful someone has taken an interest in their child and is willing to help them out. The child may tend to be passive. The child could also be attention seeking. The person who is seeking a child victim is very good at assessing children and families, and choosing a child who will or can accommodate them. The perpetrator may choose a child who is quiet, has behavior difficulties or is generally disregarded, so that even if the child does disclose, there is a good chance the child will not be believed because of their problematic personality. The perpetrator may choose a child and eventually threaten them that something terrible will happen (they will kill their mommy) if they speak up. Or, the perpetrator may shower the child with gifts to buy their silence and acceptance (13). Generally, whether within the family or the community at large, the perpetrator may be defined as a pedophile or a child molester. A pedophile is uniquely sexually attracted to children; their child victims are usually extra-familial and much of the pedophile's time is invested in accessing children. Child molesters, in contrast, may reach out to children in times of stressful life events or emotional struggles, can have an adult sexual relationship, and have fewer child victims and lower recidivism rates than the pedophile (14).

As discussed, the child's physical examination result is often normal. The child may show behavioral symptoms or clinical signs that they are experiencing sexual abuse, although these effects can be nonspecific, such as: changes in sleeping or eating, not wanting to visit or stay with someone, irritable, clingy, sexualized behavior, change in school or activity performance, feeling down or withdrawn, acting out, running away or using drugs, abdominal pain, new onset wetting or stooling, constipation or diarrhea, vaginal or penile discharge, dysuria, genital or anal bleeding and pregnancy (15). The child may not necessarily present with any specific behavioral or physical manifestations of sexual abuse. 


\section{Child sexual abuse in the community}

The veil of secret child sexual abuse experiences go beyond familial situations. These situations are also prevalent in the community at large and continue to have a steady presence in the news. A major story in the United States this year was about a successful professional football coach. The former heralded Pennsylvania State football coach, Jerry Sandusky, appears to have consistently and quietly perpetrated abuse of male children for years. Even when co-workers were eyewitnesses to disturbing events between Mr. Sandusky and male boys, no definitive action was taken; no efforts were made to protect these vulnerable children (16). In 1977 Mr. Sandusky created an organization called "The Second Mile" for troubled youth. In hindsight, it appears that this institution may have provided Mr. Sandusky with ready access to potential child sexual abuse victims. Although allegations about Mr. Sandusky and children surfaced in 2001 and 2008, Second Mile board members were not notified (17). No charges resulted at that time. Mr. Sandusky was recently charged with multiple counts of child sexual abuse. His criminal trial in June, 2012, involved eight reported male victims, who testified, relaying accounts of inappropriate and intimate sexual touching by $\mathrm{Mr}$. Sandusky (18). As the verdict was considered by the jury, one of Mr. Sandusky's adopted sons sought out the prosecutor to disclose that he, too, had been sexually abused by his adoptive father. Mr. Sandusky was found guilty of 45 counts of child sexual abuse and is now facing a 60 year prison sentence. Again, the pervasive but silent nature of the abuse provided Mr. Sandusky multiple opportunities to access child victims for years, without recourse. He was even able to successfully create a non- profit institution for children in need, that provided him frighteningly easy access to them. Another community entity, the Catholic Church, continues to struggle with ongoing patterns of revelations about sexual abuse occurring within the church domain. Many adults have successfully pursued lawsuits against the church over the last decade, claiming they were sexually abused by the parish priest and the church knowingly did not protect them. Some of these revelations specifically involve supervising priests, who were aware that certain parish priests were sexually abusing children and were simply transferring them to other sites, where children would again be present and available. For the first time in the United States, a Roman Catholic priest, Monsignor William Lynn, was convicted on June 22, 2012 of child endangerment for trying to cover up claims of abuse by priests within the church. The District attorney reported "Many in the Roman Catholic Archdiocese of Philadelphia hierarchy had dirty hands. They failed to realize that the church is its people" (19).

Sexual abuse exists in our communities without borders across the world. Although clinicians in Hungary have consistently acknowledged, managed and studied the child victims of sexual abuse, providers have no legal obligation to report these cases (20). A Nigerian report from 2012 concludes that there is a "huge gap" in what medical needs exist for sexual abuse victims as compared to what is available, and cites the mandate for treatment protocols, as well as provider training (21).

\section{Child sexual abuse and the world wide web}

These sobering and significant community situations have garnered national and international attention. Child sexual abuse has continued to develop beyond national tiers, expanding to international levels with the development of the internet, easy to use and electronically accessible in seconds. Disturbingly, creation of the internet has encouraged the production and dissemination 
of child pornography, which has become a billion dollar industry (22), the magnitude of which is unlikely to be disrupted any time soon. A report from the United Nations Human Rights Council (23) estimates there are presently four million websites that involve child victims' images, with hundreds of new images produced daily. There are different types of child pornography, such as: those involving children in simulated sexual acts, child erotica where the child is partially dressed, appearing sexualized; and virtual pornography which involves morphing images, sometimes from adult images, to portray children being sexually involved. The acts can be unspeakable. The child is instructed to smile. Not unlike sexual abuse, the child often knows the pornography producer. The producer may not or may not be a pedophile, but appreciates the revenue that these photos yield. Arguably, the most daunting and powerful effect of child pornography for these thousands of child victims is the infinite inability to eradicate their personal images from the omnipresent internet. Identification of child victims is a meticulous, time consuming process for investigators, and not easily solved as the images remain in cyberspace for all to view. The geographical enormity, in conjunction with the endless potential of the internet, is encapsulated in a quote from the Human Rights report: "In 2007 Operation Carousel led to the arrest of 700 suspects in 35 countries, the confiscation of 76,000 images of children, and the identification of 31 of the children involved" (24).

Internet access and usage also ties in with the practice of child sex trafficking. Escort type services on the web have the capability to provide sex services available by a minor child to those who are willing to pay the expense. Child sex trafficking, perhaps perceived as a more 'global' form of child sexual abuse, is a lucrative and growing criminal activity, thriving in the United States and other countries. Unsavory adults prey upon vulnerable or 'throwaway' children and have created a service that produces billions of dollars (25). Children, typically teenagers but they may be younger, receive promises of attention, gifts and protection. Coming from already difficult situations, these minor children will unknowingly be exposed to sexual misuse, isolation, physical beatings, sexual such as positive HIV status - and nonsexual ailments. These children may be moved to a geographical area where they do not know the language or culture, do not know how to access the authorities, and they become hopeless and helpless, surviving but never thriving. Health care providers are encouraged to be aware of the clinical dynamics that may present with these children, should they present for care. They may be accompanied by an older male, have material items they would not be typically be capable of paying for themselves, may be pregnant or have a sexual infection, and can suffer from chronic illnesses, such as tuberculosis or deteriorating teeth. They may have been exposed to drug use so that they are more compliant. Their 'owner' or pimp may have them identified with a certain tattoo or skin marking $(26,27$, 28). A strategic one to one encounter should be employed with these children to assess their situation. If indicated, objective interpreters are essential. Recently in the United States, 79 teenagers, ages 13-17 years old, were removed from a prostitution ring and more than a hundred pimps were arrested by the Federal Bureau of Investigations (FBI). Child sex trafficking occurs everywhere, as Mr. Ernie Allen, president of the National Center for Missing and Exploited Children said recently, "It is clear that child prostitution and sex trafficking do not just occur somewhere else on the other side of the world...these insidious crimes are occurring in American cities and the victims are American kids (29)". 


\section{Child sexual abuse education and prevention}

Child sexual abuse remains problematic in society in 2012 (30). Sexual abuse of children continues to exist on every level of our sphere of life - within families, communities, the nation and the world. Ideas for prevention of child sexual abuse are essential at every level in our environment. This prevention can start at home, with the utilization of safe internet practices, awareness of where children are and who is taking care of them, educating our children about boundaries and appropriate interaction with others, company policies that demand safety for children, such as background checks, no one to one or hidden interactions with adults vs. children, and all interactions observable at any time.

Silva (31) presents the plight of Philippine children, whose families are destitute and their home life conditions require the children to live and work on the street, placing them in dangerous and potentially abusive situations. A group of "street educators" with Childhope make continuous efforts for these high risk children, to intervene in a holistic fashion, providing education, safety, counseling and hope for the future. A shelter is also available to provide the children a safe haven.

Education about the internet should include discussions about the incredible opportunities it provides to learn about the world, but also how it can be misused for criminal activity that harms children, such as online grooming, where nineteen percent of teens have had a sexual solicitation online (32). The internet in association with sex trafficking and the process of sex trafficking itself present another major challenge to our communities to protect our children. Internet service providers are expected to report illegal activity on their web sites. International groups are organizing to address the plight of these disadvantaged children. "The Defenders", a group formed as an initiative of Shared Hope International, describes their strategy "...to recruit and mobilize men to join the fight against the use of our children in the commercial sex industry of porn, stripping and prostitution" (33).

As a health care provider, having a high index of suspicion when seeing our pediatric patients and reporting any concerning clinical presentations suggesting abuse, is essential to the child's chances for health and safety. The provider should include basic guidelines about sexual abuse to parents and children during their medical visits. First and foremost, the provider can encourage and support prevention of child sexual abuse by providing information to avoid child victimization. The internet provides several options for sexual abuse prevention materials, including Prevent Child Abuse America, Stop It Now, Darkness to Light and in the United States, state crime victim publications $(34,35,36)$. Understandably, the health care provider's time is extremely limited regarding providing preventive discussions. The materials provided by these organizations, such as handouts, bookmarks and coloring books, are an accessible, efficient method of incorporating prevention into a clinical visit. The author's institution has made ongoing efforts to provide doctors in training with pertinent content lectures and then provide the prevention materials in the well child clinic, where slightly more time is allotted for discussion than sick visit time slots. The provider will also need to know about resources for the child or teen that has already been victimized and needs medical, mental health and protective interventions. Access to care and follow up for these children is crucial for their well-being and recovery. Finally, the health care provider is not immune to the effects of child exploitation. Unfortunately doctors have been implicated in child sexual abuse investigations (37). Therefore, the provider's office environment should be protective of 
all children and have protocols in place for when an office visit requires certain actions, such as disrobing, anogenital exams, or one to one discussions (38).

\section{Conclusion}

In conclusion, child sexual abuse persists unthreatened in our world in 2013. Society must be aware that there is a problem before the problem can be addressed. A community can only be receptive when there are believing

\section{References}

1. Wolak J, Finkelhor D, Mitchell K. Child pornography possessors: trends in offender and case characteristics. Sex Abuse. 2011;(23):22-42.

2. Finkelhor D, Jones L. Have sexual abuse and physical abuse declined since the 1990s? Crimes Against Children Research Center. University of New Hampshire. [November 2012]. Available from: http://www.unh.edu/ccrc/pdf/CV267_ Have $\% 20$ SA $\% 20 \% 20$ PA $\% 20$ Decline_FACT $\% 20$ SHEET_11-7-12.pdf

3. Summit R. The child sexual abuse accommodation syndrome. Child Abuse and Neglect. 1983;(7):177-93.

4. Berenson A, Chacko M, Wiemann C, Mishaw C, Friedrich W, Grady J. A case control study of anatomic changes resulting from sexual abuse. American Journal of Obstetrics and Gynecology. 2000;(182):820-31.

5. Kellogg N, Menard S, Santos A. Genital anatomy in pregnant adolescents: "Normal" does not mean "Nothing Happened”. Pediatrics. 2004;(113):e6769.

6. Kellogg N, the American Academy of Pediatrics. The evaluation of sexual abuse in children. Pediatrics. 2005;(116):506-12.

7. Girardet R, Lahoti S, Howard L, Fajman N, Sawyer M, Driebe E, et al. Epidemiology of sexually transmitted infections in suspected child victims of sexual assault. Pediatrics. 2009;(124):79-86.

8. Pickering LK, editor. Red Book 2012 Report of the Committee on Infectious Diseases. 29th ed. Elk Grove Village: American Academy of Pediatrics; 2012. members who understand these conflicts do exist for the youngest members of our society and beg for intervention, action and change. It is essential that health care providers are aware of the family, community and worldly conditions that so readily promote child sexual abuse, and be ready to advocate and protect the most vulnerable members of our society.

Conflict of interest: The author declare that she has no conflict of interest. This article was not sponsored by any external organization.

9. Giardino A, Finkel M. Evaluating child sexual abuse. Pediatric Annals. 2005;(34):382-94.

10. Schaefer G, Mundt I, Ahlers C, Bahls C. Child sexual abuse and psychological impairment in victims: Results of an online study initiated by victims. J Child Sex Abus. 2012;(21):343-60.

11. Fortin K, Jenny C. Sexual abuse. Pediatrics in Review. 2012;(33):19-32.

12. Holmes W, Slap G. Sexual abuse of boys: definition, prevalence, correlates, sequelae and management. JAMA. 1998;(280):1855-62.

13. Salter Anna. Truth, lies and sex offenders. Specialized Training Services. Available from: www. specializedtraining.com

14. The Association for the Treatment of Sexual Abusers. Pedophiles and Child Molesters: the differences. [February 17, 2010]. Available from: http://www.atsa.com/ppPedophiles.html

15. Heger AH, Emans JS, Muram D. Evaluation of the sexually abused child. A medical textbook and photographic atlas. 2nd ed. Oxford: Oxford University Press; 2000.

16. Testimony at Sandusky Trial shows missed chances. Associated Press Sports. [cited 2012 Jun 20]. Available from: http://nbcsports.msnbc.com/ id/47842972/ns/sports-college_football/

17. The future of Jerry Sandusky's charity, The Second Mile. Associated Press. [cited 2012 Jun 26]. Available from: http://www.lehighvalleylive. com/breaking-news/index.ssf/ 2012/06/the_future_of_jerry_sandusky 
18. Testimony at Sandusky Trial shows missed chances. Associated Press Sports. [cited 2012 Jun 20]. Available from: http://nbcsports.msnbc.com/ id/47842972/ns/sports-college_football/

19. Dale, M. Philadelphia priest guilty in cover up. Stltoday. [cited 2012 Jun 23] Available from: http:// www.stltoday.com/news/national/philadelphiapriest-guilty-in-cover-up/article_f51294bb-1d9f5f6a-a6d7-eadc8de912fa.html

20. Csorba R, Tsikouras P, Lampe R, Poka R. The sexual abuse of female children in Hungary: 20 years' experience. Archives of Gynecology and Obstetrics. 2012;286:161-6.

21. Ige O, Fawole O. Evaluating the medical care of child sexual abuse victims in a general hospital in Ibadan, Nigeria. Ghana Med J. 2012;46;(1):22-6.

22. Broughton, D. Internet child sexual exploitation. In: Jenny, C, editor. Child abuse and neglect diagnosis, treatment and evidence. St. Louis: Elsevier Saunders; 2011.p.142-146.

23. Maalla NM. Promotion and protection of all human rights, civil, political, economic, social and cultural rights, including the right to development. Report of the special rapporteur on the sale of children, child prostitution and child pornography.United Nations, General Assembly, Human Rights Council. Twelfth Session, Agenda item 3. July 13, 2009. p. 1- 26.

24. Maalla NM. Promotion and protection of all human rights, civil, political, economic, social and cultural rights, including the right to development. Report of the special rapporteur on the sale of children, child prostitution and child pornography. United Nations, General Assembly, Human Rights Council. Twelfth Session, Agenda item 3. July 13, 2009. p. 21.

25. Tracy EE, Konstantopoulos WM. Human trafficking: a call for heightened awareness and advocacy by obstetrician-gynecologists. Obstet Gynecol. 2012;119(5):1045-7.

26. McClain G, Garrity S. Sex trafficking and the exploitation of adolescents. J Obstet Gynecol Neonatal Nurs. 2011;(40):243-52.

27. Silverman JG, Decker MR, Gupta J, Maheshwari A, Willis BM, Raj A. HIV prevalence and predic- tors of infection in sex-trafficked Nepalese girls and women. JAMA. 2007;298(5):536-42.

28. O'Callaghan MG. Human trafficking and the dental professional. J Am Dent Assoc. 2012;143(5):498-504.

29. Black, J. MSNBC.msn.com 79 teen prostitutes taken off the streets in nationwide crackdown. [cited 2012 Jun 26]. Available from: http://usnews. msnbc.msn.com/_news/2012/06/25/1240344179-teen-prostitues-taken-off

30. Everitt R, Reed P, Kelly P. Medical assessment for child sexual abuse: a post-code lottery? J Paediatr Child Health. 2012;48(5):389-94.

31. Silva TL. Preventing child exploitation on the streets in the Philippines. Lancet. 2002 9;360(9344):1507.

32. Whittle H, Hamilton-Giachritis C, Beech A, Collings G. A review of online grooming: characteristics and concerns. Aggression and Violent Behavior. 2012;18(2013):62-70.

33. Sharedhope.org.[homepage on the Internet] The Defenders USA, Available from: https://www. sharedhope.org/the defenders/TakeAction/The DefendersPledge.aspx

34. PreventchildabuseAmerica.org. [homepage on the Internet]. Illinois: Prevent Child Abuse America; c1995-2012[cited 2013 Jan 15]. Available from: http://www.preventchildabuse.org/publications/index.shtml

35. Stopitnow.org [homepage on the Internet] Massachusetts: StopItNow Inc; c2008-2012. [cited 2013 Jan 15]. Available from: http://www.stopitnow.org/resources

36. Darknesstolight.org. [homepage on the internet]. South Carolina: Darkness to Light; c2010 [cited 2013 Jan 15]. Available from: http://www.d2l.org/ site/c.4dICIJOkGcISE/b.6143703/k.15DC/7_ Steps_to_Protecting_Our_Children.htm

37. Pratt, M. Lawsuit alleges sex abuse by Boston pediatrician. News Observer. [cited 2012 Nov 28]. Available from: http://www.newsobserver. com/2011/02/18/997635/lawsuit-alleges-sexabuse-by-boston.html

38. Committee on Child Abuse and Neglect. Protecting children from sexual abuse by health care providers. Pediatrics. 2011;128(2):407-26.

Citation: Pfitzer JL. Sexual abuse today: Present and pervasive. Paediatrics Today. 2013;9(1):5-12. 